\title{
AVALIAÇÃo DA CORRELAÇÃO DE SOROLOGIA E TESTE DE ÁCIDO NUCLEICO EM DOADORES DE SANGUE REAGENTES PARA O VÍRUS DA IMUNODEFICIÊNCIA HUMANA
}

\section{EVALUATION OF THE CORRELATION OF SEROLOGY AND NUCLEIC ACID TESTING IN ANTI-HIV REAGENT BLOOD DONORS}

Clin Biomed Res. 2018;38(4):332-338

1 Curso de Biomedicina, Centro Universitário Metodista (IPA). Porto Alegre, RS, Brasil.

2 Serviço de Hemoterapia, Laboratório Marques Pereira. Porto Alegre, RS, Brasil.

Autor correspondente: Laura Vicedo Jacociunas laura.jacociunas@ipa.metodista.br Centro Universitário Metodista (IPA) Rua Cel. Joaquim Pedro Salgado, 80. 90240-060, Porto Alegre, RS, Brasil.

\section{Thiago Ferreira DAvila1', Deborah Veiga Santos², Cristine Blume Brietzke ${ }^{2}$, Laura Vicedo Jacociunas ${ }^{1}$}

\section{RESUMO}

Introdução: As transfusões sanguíneas começaram a ser realizadas no Brasil no século XX como forma de tratamento terapêutico. Com a descoberta do vírus HIV, a segurança do sangue doado passou a ser prioritária. Assim, candidatos à doação de sangue são submetidos a uma triagem clínica e sorológica, além do teste de ácido nucleico (NAT), obrigatório desde 2014 nos bancos de sangue.

Métodos: Estudo retrospectivo através da análise de dados dos doadores de sangue de um Serviço de Hemoterapia em Porto Alegre/RS, nos anos de 2015 a 2017. Avaliando resultados sorológicos e da técnica NAT para HIV.

Resultados: Das 28.625 amostras de usuários do serviço de hemoterapia, 41 $(0,14 \%)$ foram reagentes para o HIV e $21(0,07 \%)$ foram reagente para o teste NAT. Estes dados demonstram uma reatividade duas vezes maior nas amostras de bolsas testadas sorologicamente quando comparadas com a metodologia utilizada no NAT.

Conclusão: O avanço científico e tecnológico tem auxiliado no que se refere a redução dos riscos de transmissão de doenças infecto-contagiosa por transfusão sanguínea. O teste NAT teve um acréscimo significativo na pesquisa dos vírus para a segurança na liberação de hemocompoentes. O teste foi introduzido nas rotinas de banco de sangue no intuito de reduzir o período de janela imunológica quando comparado aos testes sorológicos, fato este não observado nos anos de coleta de dados no Serviço de Hemoterapia referido neste estudo.

Palavras-chave: Sorologia; NAT; HIV; segurança transfusional; hemoterapia

\section{ABSTRACT}

Introduction: Blood transfusions began to be performed in Brazil in the twentieth century as a form of therapeutic treatment. With the discovery of the HIV, the safety of donated blood became a priority. Therefore, candidates for blood donation are subjected to clinical and serological screening, in addition to the nucleic acid test (NAT), which has been mandatory since 2014 in blood banks.

Methods: We conducted a retrospective study using data from blood donors at one hemotherapy service in Porto Alegre, state of Rio Grande do Sul, from 2015 to 2017. Serological and NAT results for HIV were evaluated.

Results: Of the 28,625 samples of users of the hemotherapy service, $41(0.14 \%)$ were HIV reagents and $21(0.07 \%)$ had a reagent result for the NAT test. These data demonstrate a two-fold higher reactivity in the samples of serologically tested units as compared to the methodology used in NAT. 
Conclusions: Studies with different time periods are needed to further explain this association. The NAT test had a significant increase in the search for viruses and the safety in the release of blood components. The test was introduced in the blood bank routines in order to reduce the window period when compared to serological tests, a fact that was not observed in the years of data collection in the hemotherapy service referred to in this study.

Keywords: Serology; NAT; HIV; transfusion safety; hemotherapy

Há muitos anos, a doação de sangue era considerada apenas como a transmissão de material biológico, sem grandes riscos ao receptor ${ }^{1}$. Entretanto, a partir de 1980, com a descoberta do vírus da imunodeficiência humana (HIV), causador da Síndrome da Imunodeficiência Adquirida (SIDA), a segurança do sangue doado passou a ser prioridade nos hemocentros. O sangue por ser um tecido vivo é capaz de transmitir uma série de patologias. É necessário que o material coletado siga rigorosos padrões de qualidade, desde o momento da coleta até a seleção e proteção ao receptor ${ }^{2,3}$. Desta forma, ao longo dos anos observou-se um crescimento significativo no que se refere a cuidados com a segurança transfusional e a necessidade de realização de testes de triagem para doenças infecciosas cada vez mais sensíveis fez-se necessário ${ }^{4}$.

Os procedimentos hemoterápicos, no Brasil, seguem a portaria $n^{\circ} 158$, de 04 de Fevereiro de 2016, DOU de 05/02/2016 ( ${ }^{\circ}$ 25, Seção 1, pág. 37) da Agência Nacional de Vigilância Sanitária (ANVISA) ${ }^{5}$. Esta conduta visa atenuar as possibilidades de transmissão de patógenos infecciosos nos hemocomponentes a serem transfundidos. O processo de transfusão é dividido em etapas que vão desde a captação do doador até a transfusão de sangue ao receptor. A primeira etapa é constituída pela triagem clínica que compreende um questionário onde o candidato deverá responder algumas perguntas, sempre avaliando seu trajeto clínico e relacionando com seu comportamento, visando detectar riscos eminentes. A segunda etapa refere-se à triagem sorológica que busca evitar infecções por vários agentes etiológicos. Após a doação o sangue passa por uma triagem laboratorial que contém testes imunohematológicos, sorológicos, e complementares, como o Teste de Ácido Nucléico (NAT). O NAT consiste em detectar ácidos nucleicos do HIV, que detecta o vírus de forma precoce em comparação com os testes sorológicos ${ }^{5,6}$

A triagem laboratorial exigida pela portaria vigente, baseia-se na realização de exames laboratoriais, sorológicos, para a determinação de marcadores para as seguintes patologias: sífilis, Doença de Chagas, Hepatite B, Hepatite C, Vírus da Imunodeficiência Humana (HIV) / Síndrome da Imunodeficiência Adquirida (AIDS), Vírus Linfotrópico da Célula T
Humana tipo I e/ou tipo II (HTLV I/II) $)^{4,7}$. No que diz respeito a investigação da presença do vírus HIV no sangue doado, a detecção de ácidos nucleicos do vírus também é obrigatória em toda a Hemorrede Nacional desde fevereiro de 2014, através da portaria 2712 de 12 de novembro de $2013^{7}$.

O vírus da imunodeficiência humana é um retrovírus, classificado na subfamília dos Lentiviridae com material genético de RNA ${ }^{8,9}$. Existem dois tipos virais: o HIV tipo 1 que é encontrado em todos os continentes, sendo responsável pela grande maioria dos casos, e o tipo 2, que ocorre de forma restrita e possui menor virulência ${ }^{10}$. Além disso, o HIV apresenta heterogeneidade gênica, resultando em modificações do fenótipo com diferentes padrões de infecção e progresso da doença ${ }^{11,12}$.

Para a determinação do HIV, existem testes sorológicos por métodos de ELISA (Enzyme linked immunosorbent assay), ELFA (Enzyme linked fluorescent assay), IFA (Immunofluorescence assay), PA (Particle agglutination assay), CIA (Chemiluminescence assays), MEIA (Microparticle enzyme immunoassay) e NAT (Nucleic acid amplification test $)^{13}$. O desenvolvimento de técnicas moleculares vem aumentando a sensibilidade e especificidade dos testes realizados e consequentemente reduzindo o período de detecção da janela imunológica, o que culmina uma maior segurança transfusional ${ }^{14}$. A mais recente metodologia aplicada na triagem de doadores de sangue é o teste NAT, que utiliza a técnica de biologia molecular chamada PCR (Reação em Cadeia da Polimerase) para amplificar e detectar o RNA viral presente no plasma. Desta forma, é mais sensível que os testes sorológicos, considerando que baixos níveis de RNA viral podem ser detectados no início da infecção. O NAT é mais sensível que as técnicas sorológicas contribuindo para a redução da janela imunológica ${ }^{15}$. Estudos referem que para o HIV, a introdução do teste NAT reduz de 30 para 7 a 10 dias do período mínimo para detecção do vírus ${ }^{16}$.

Por exigência do Ministério da Saúde (MS) todos os testes para a investigação de anticorpos contra o HIV, ou detecção combinada do anticorpo contra HIV, incluindo pesquisa de antígeno p24 do vírus e detecção de ácidos nucleicos devem ser realizados 
no material coletado. Caso algum desses testes apresente resultado positivo, a bolsa de sangue deve ser descartada e o doador chamado para receber maiores orientações de como proceder ${ }^{5}$. De 2007 a Junho de 2017, foram notificados no SINAN (Sistema de Informação de Agravos de Notificação) 194.217 casos de infecção pelo HIV no Brasil, sendo: no Sudeste foram $96.439(49,7 \%)$, no Sul $40.275(20,7 \%)$, no Nordeste 30.297 (15,6\%), no Norte 14.275 (7,4\%) e no centro-oeste 12.931 (6,7\%). Ainda de acordo com o SINAN, no mesmo período em relação ao sexo, houve um total de $131.969(67,9 \%)$ casos em homens e $62.198(32,1 \%)$ casos em mulheres ${ }^{17}$. Estudo epidemiológico em um banco de sangue na cidade de Porto Alegre - RS aponta que nos anos de 2014,2015 e 2016 a prevalência foi de 0,18\%, $0,14 \%$ e $0.16 \%$ respectivamente ${ }^{18}$.

Diante do exposto, o presente estudo teve por objetivo avaliar a prevalência do HIV através de testes sorológicos e teste complementar NAT, em doadores de sangue de um banco de sangue de Porto Alegre/RS no período de 2015 a 2017 a fim de demonstrar a correlação de detecção de antígeno e anticorpo de ambas as metodologias.

\section{MÉTODOS}

Realizou-se um estudo retrospectivo, através da análise das informações de doadores de sangue contidas no banco de dados do Banco de Sangue do Laboratório Marques Pereira - Porto Alegre, Rio Grande do Sul, referente ao período compreendido entre o dia $1^{\circ}$ de janeiro de 2015 a 31 de dezembro de 2017. Este estudo foi registrado e aprovado pelo Comitê de Ética em Pesquisa do IPA, via Plataforma Brasil, com parecer número 2.178.342.

A amostra do presente estudo foi constituída pelos dados de 28.625 usuários do Serviço de Hemoterapia do Laboratório Marques Pereira. Os registros dos dados foram avaliados através de um software de gestão para serviços de hemoterapia (Hemodot), e por meio deste, coletadas as informações referentes à detecção de sorologia positiva HIV I/II e teste NAT, a fim de promover uma análise da frequência destes dados na população estudada.

Os resultados foram expressos em número total e porcentagem. Os testes sorológicos utilizados pelo banco de sangue são qualitativos tratando-se de imunoensaios de micropartículas por quimioluminescência com especificidade de $99,5 \%$ e sensibilidade de $100 \%$ e estão de acordo com o preconizado pelo Ministério da Saúde. O valor de índice a ser considerado, recomendado pelo fabricante $\left(\mathrm{Abbott}^{\circledR}\right)$ é $\geq$ a 1 sorologia reagente $\mathrm{e}$ $<1$ sorologia não reagente, no entanto o serviço trabalha com uma margem de segurança de 15\% (zona cinza), sendo que os resultados que estiverem nesta faixa serão liberados como indeterminados, e o doador será convocado a retornar ao serviço para nova coleta. Com relação ao teste NAT, o Serviço de Hemoterapia terceiriza os testes ao Laboratório Imunolab e Hemosc, ambos atendem as normativas estipuladas pela legislação vigente - Portaria 158, de 4 de fevereiro de 2016.

O teste NAT é realizado em pool de 6 amostras de doadores. Tal conjunto de pool deve atender a sensibilidade da amostra do doador, em que para aceitação, conforme legislação, a sensibilidade deve ser de $100 \%$, não aceitando falsos negativos e a especificidade acima de $99 \%$. Nos casos em que um grupo de testes apresentar resultado de NAT positivo, o pool é desmembrado e as amostras testadas individualmente (fabricante: Roche ${ }^{\circledR}$ ) para identificação dos agentes infecciosos em questão e de qual/(ais) amostra/(s) positivaram (Imunolab). No caso do Hemosc, são empregadas técnicas de quimioluminescência aprovadas pelo Ministério da Saúde. Os vírus das hepatites B e C e HIV são verificados por biologia molecular através do NAT HIV/HCV/HBV Biomanguinhos-FIOCRUZ, que possibilitam a detecção do genoma viral nas amostras dos doadores.

\section{RESULTADOS}

O número total de candidatos à doação no período compreendido entre os anos de 2015 a 2017 foi de 28.625 doadores, sendo que o serviço recebeu por ano 10.009 doadores em 2015, 9.469 em 2016 e 9147 em 2017. Nestes três anos avaliados, o total de bolsas sorologicamente reagentes para HIV foi de $41(0,14 \%)$, e as bolsas reagentes para o teste NAT foi de $21(0,07 \%)$. Os dados de sorologia e NAT reagentes, ano a ano, estão demonstrados na tabela 1.

\section{DISCUSSÃO}

O processo transfusional no Brasil e no mundo é uma medida terapêutica amplamente utilizada ${ }^{7,18}$. Apesar do desenvolvimento de novas tecnologias para triagem sorológica no diagnóstico de doenças veiculadas pelo sangue e da adoção de medidas de segurança na triagem clínica com o intuito de eliminar os doadores com comportamento de risco, a transmissão do HIV ainda é um desafio nos serviços hemoterápicos devido ao risco de não detectar durante a janela imunológica ${ }^{16,18,19}$.

A transmissão do HIV por meio de transfusão sanguínea representa um problema de saúde pública e um desafio para os serviços hemoterápicos em todo 
Tabela 1: Total de bolsas reagentes ao ano para HIV (Sorologia e NAT).

\begin{tabular}{lcccccc}
\hline & Total & $(\mathbf{\%})$ & Homens & $\mathbf{( \% )}$ & Mulheres & (\%) \\
\hline $\mathbf{2 0 1 5}$ & & & & & & \\
Bolsas Reagentes para sorologia HIV & 14 & $(0,14 \%)$ & 9 & $(0,09 \%)$ & 5 & $(0,05 \%)$ \\
Bolsas Reagentes para HIV NAT & 7 & $(0,07 \%)$ & 5 & $(0,05 \%)$ & 2 & $(0,02 \%)$ \\
Total de Doadores/Ano & 10009 & $(100 \%)$ & 14 & $(0,14 \%)$ & 7 & $(0,07 \%)$ \\
$\mathbf{2 0 1 6}$ & & & & & & \\
Bolsas Reagentes para sorologia HIV & 15 & $(0,16 \%)$ & 4 & $(0,04 \%)$ & 11 & $(0,12 \%)$ \\
Bolsas Reagentes para HIV NAT & 9 & $(0,09 \%)$ & 4 & $(0,04 \%)$ & 5 & $(0,05 \%)$ \\
Total de Doadores/Ano & 9469 & $(100 \%)$ & 8 & $(0,08 \%)$ & 16 & $(0,17 \%)$ \\
$\mathbf{2 0 1 7}$ & & & & & & \\
Bolsas Reagentes para sorologia HIV & 12 & $(0,13 \%)$ & 7 & $(0,07 \%)$ & 5 & $(0,05 \%)$ \\
Bolsas Reagentes para HIV NAT & 5 & $(0,05 \%)$ & 2 & $(0,02 \%)$ & 3 & $(0,03 \%)$ \\
Total de Doadores/Ano & 9147 & $(100 \%)$ & 9 & $(0,010 \%)$ & 8 & $(0,09 \%)$ \\
\hline
\end{tabular}

Fonte: Elaborado pelo autor (2018).

o mundo ${ }^{19,20}$. A constante adequação dos bancos de sangue, em consonância com a legislação vigente, vem tornando o processo de transfusão sanguínea cada vez mais seguro. De acordo com o estudo de Pereira e Bonafé, 2015 realizado no banco de sangue Dom Bosco (Maringá/PR), no período de 2004 a 2013, mostrou que prevalência de HIV foi de $0,05 \%$, sendo um indicativo de redução de casos de HIV devido a implantação de programas de prevenção ${ }^{21}$.

Neste contexto, torna-se imprescindível ressaltar que, para garantir segurança e qualidade no processo transfusional, todos os procedimentos realizados nos serviços de hemoterapia devem obrigatoriamente obedecer a rígidos padrões de qualidade, por profissionais capacitados e utilizando técnicas específicas e adequadas.

Os resultados apresentados demonstram uma reatividade duas vezes maior nas amostras de bolsas testadas sorologicamente quando comparadas com a metodologia utilizada no NAT (figura 1). Resultados estes, que podem ser associados a amostras inconclusivas sorologicamente, bem como sua detecção ser mais tardia, sendo detectada após o aparecimento dos anticorpos.

Considerando que o presente estudo avaliou os dados de 2015 a 2017 do Banco de Sangue do Laboratório Marques Pereira, constatou-se que teste do NAT teve um grande acréscimo na pesquisa dos vírus para a liberação de hemocomponentes. O teste foi introduzido nas rotinas de banco de sangue obrigatoriamente desde o ano de 2014, no intuito de reduzir o período de janela imunológica quando comparado aos testes sorológicos, fato este não observado nos anos de coleta de dados no serviço de hemoterapia referido neste estudo ${ }^{18}$. Como a implantação do NAT no Brasil ainda é muito recente, estudos sobre a sua efetividade, representada pelo número de amostras reagentes,

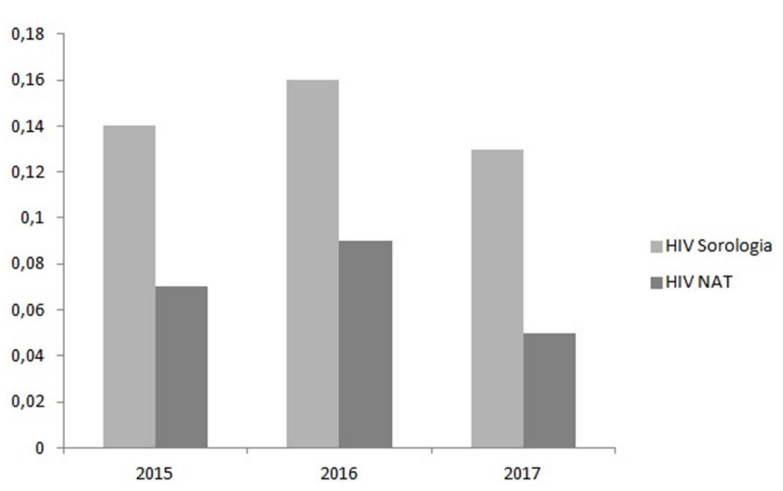

Figura 1: Prevalência de HIV nos testes sorológicos e NAT das amostras do serviço de Homoterapia do Laboratório Marques Pereira do ano de 2015 a 2017, expressa em \%. Fonte: Elaborado pelo autor (2018).

detectando a presença do RNA viral e com sorologia negativa, ainda não foram realizadas no Brasil em grande escala, mas podem ser observados em outros países conforme relatado pela Rede Brasileira de Avaliação de Tecnologias em Saúde. Nos Estados Unidos, por exemplo, onde a rotina do NAT em bancos de sangue já está a mais tempo consolidada, conforme Azevedo, o risco estimado da transmissão de HIV por transfusão nos serviços de hemoterapia americanos, era de 1 para 1.468 .000 pessoas, caiu de 1 para 2.135.000 pessoas ${ }^{22,23}$.

De acordo com a legislação vigente e com a atenção dos serviços de hemoterapia, é evidente que vem aumentando a segurança nos processos de transfusão sanguínea, tanto para o receptor quanto para o doador ${ }^{5}$. Estas medidas tornam menores os riscos de transmissão de doenças infecciosas por transfusão, ainda mais raras ${ }^{4}$. Corroboram com essa informação os dados do estudo de Velati et al. ${ }^{24}$, onde foram detectadas janelas imunológicas apenas pelo teste NAT, sendo 27 para HCV e 14 para HIV. 
No referido estudo, foi observado que no período de 6 anos a redução da correlação dos dados dos testes sorológicos e do teste NAT, o que torna mais segura a qualidade do sangue ao paciente receptor ${ }^{24}$.

Observou-se também os dados apresentados no estudo de Lima (2011), o quão é importante a inclusão do teste NAT para a redução da janela imunológica em doenças como o HIV e HCV, bem como para resolução de casos dados como falsopositivos encontrados nos testes sorológicos, que levam a maiores consequências legais ao banco de sangue ${ }^{25}$.

De acordo com o Boletim epidemiológico divulgado até Junho de 2017, foram registrados $576.245(65,3 \%)$ casos de AIDS em homens e 306.444 (34,7\%) em mulheres. No período de 2002 a 2008, a razão de sexos, foi expressa pela relação entre o número de casos de AIDS em homens e mulheres, manteve-se e 15 casos em homens para cada 10 casos em mulheres no presente estudo, a prevalência, nos anos de 2015 e 2017 foi maior em homens ${ }^{17}$. Estes dados corroboram com estudo de Silva, 2016, que avaliou 28.173 amostras nos anos de 2014 a 2016 e também verificou maior prevalência no sexo masculino ${ }^{18}$. No estudo de Costa, et al., 2013, foi avaliado um total de 8.838 amostras nos de 2010 a 2013 onde foi constatada a prevalência do HIV em 7 doadores, sendo que 6 destes eram do sexo masculino $(85,7 \%)$ e apenas 1 doador do sexo feminino, representando $(14,3 \%)^{19}$.

Estudos realizados no Hemocentro de Goiânia avaliou a soroprevalência de HIV em doadores de sangue nos anos de 2002 e 2003, de 41.033 bolsas coletadas, 136 bolsas foram reagentes para o vírus do HIV, sendo a grande maioria $(83,1 \%)$ do sexo masculino, dados estes que convergem com os apresentados neste estudo ${ }^{26}$.

Estudo de Busch et al. (2005) publicou o resultado monitorado durante três anos, após a inclusão de triagem laboratorial de doadores de sangue com a tecnologia NAT nos EUA, a conclusão foi que após a implementação, o teste reduziu o risco de transmissão para o HIV em transfusões sanguíneas para o aproximado de 1 em 2,3 milhões de unidades e 1,8 milhões de unidades respestivas ${ }^{27}$. Fica claro que é indispensável dar continuidade a aplicação dos testes citados para uma maior confiabilidade no momento da transfusão sanguínea, aumentando a segurança e a sensibilidade nas triagens dos doadores.

É comprovado que o avanço científico e tecnológico tem auxiliado no que se refere a redução dos riscos de transmissão de doenças infecto contagiosas por transfusão sanguínea. Sabemos que o teste ELISA da quarta geração atinge na prática quase 100\% de sensibilidade. Ainda assim, atualmente, por ser obrigatório o uso da técnica de amplificação do ácido nucleico para HIV em bancos de sangue, vem diminuindo o período da janela imunológica.

Com base nos padrões de sensibilidade e especificidade de ambas metodologias ressalta-se que numa infecção recente o organismo apresenta os antígenos aumentados, sendo estes detectados pelo teste NAT. A fase inicial da infecção (aguda) até o estabelecimento de carga viral antecede a detecção de anticorpos contra o vírus. Sendo assim, com o passar do tempo diminuem-se os antígenos e ocorre a elevação dos anticorpos, que, neste caso, a sorologia é capaz de detectar ${ }^{28,29}$.

Contudo a discrepância entre os resultados sorológicos e teste NAT apresentados pode ser explicada por duas situações, sendo a primeira relacionada com resultados falso-positivos encontrados no teste de triagem sorológica, visto que o mais importante para os testes de triagem realizados em bancos de sangue é a sensibilidade, acima da especificidade para se garantir a exclusão de possibilidade de transmissão de doenças infecciosas via transfusão sanguínea; e, a segunda situação está relacionada com a existência de indivíduos que portam o vírus e que apresentam um alto título de anticorpos circulantes (detectáveis pela sorologia) e baixa carga viral (não detectáveis pelo teste NAT) ${ }^{30}$.

Portanto, conforme a tabela 1 , do total de 41 indivíduos (2015-2017) com sorologia reagente, 21 apresentaram tanto detecção de anticorpos quanto de antígenos, desta forma, NAT positivo concomitante com a técnica de quimioluminescência.

Deve-se salientar que este estudo teve como objetivo avaliar a prevalência do HIV através de testes sorológicos e teste complementar NAT, a fim de demonstrar a correlação de detecção de antígeno e anticorpo de ambas as metodologias.

Contudo, ainda são poucos os estudos com evidência clínica na literatura de dados mais concretos que nos levem para o assunto, dessa forma, é imprescindível maiores estudos com períodos diferentes de tempo para a pesquisa de resultados satisfatórios e que expliquem ainda mais os resultados obtidos nesse estudo. Dessa forma, esse estudo possibilita outras formas de admiração com relação a associação dos testes sorológicos e o teste NAT nos bancos de sangue em casos de HIV.

\section{Conflitos de Interesse}

Os autores declaram não ter conflitos de interesse. 


\section{REFERÊNCIAS}

1. Rodrigues RSM, Reibnitz KS. Estratégias de captação de doadores de sangue: uma revisão integrativa da literatura. Texto Contexto - Enferm. Florianópolis. 2011;20(2):384-91.

2. Liberato SMD, Costa IKF, Pessoa CM, Nogueira MAC, Araújo MDMN, Torres GV. Perfil dosdoadores de sangue do Hemocentro Público de Natal/ RN. Rev Pesqui Cuid Fundam Online. 2013;5(1):3523-30.

3. Zago A, Silveira MF, Dumith S. Prevalência de doação de sangue e fatores associados. Rev Saude Publica. 2010;44(1):11220. http://dx.doi.org/10.1590/ S0034-89102010000100012. PMid:20140335.

4. Seitz R, Heiden M. Quality and safety in blood supply in 2010. Transfus Med Hemother. 2010;37(3):112-7. http://dx.doi.org/10.1159/000314497. PMid:20577599.

5. Brasil. Ministério da Saúde. Portaria $n^{\circ} .158$, de 04 de fevereiro de 2016. Redefine o regulamento técnico de procedimentos hemoterápicos. Diário Oficial da República Federativa do Brasil. 2016 Fev 05;25(1):37

6. Monteiro DK, Comparsi B. Principais fatores associados a inaptidão temporária e permanente de candidatos á doação de sangue. Rev Saúde Integrada. 2015;8:15-6.

7. Rohr JI, Boff D, Lunkes DS. Perfil dos candidatos inaptos para doação de sangue no serviço de Hemoterapia do Hospital Santo Ângelo, RS, Brasil. Rev Patol Trop. 2012;41(1):2735. http://dx.doi.org/10.5216/rpt. v41i1.17750.

8. Clement ME, Okeke NL, Hicks CB. Treatment of syphilis: a systematic review. JAMA. 2014;312(18):190517. http://dx.doi.org/10.1001/ jama.2014.13259. PMid:25387188.

9. Brito AM, Szwarcwald CL, Castilho EA. Fatores associados à interrupção de tratamento antirretroviral em adultos com AIDS. Rev Assoc Med Bras. 2006;52(1):8692. http://dx.doi.org/10.1590/ S0104-42302006000200017. PMid:16767332.

10. Marlink R, Kanki P, Thior I, Travers K, Eisen G, Siby T, et al. Reduced rate of disease development after
HIV-2 infection as compared to HIV-1. Science. 1994;265(5178):158790. http://dx.doi.org/10.1126/ science.7915856. PMid:7915856.

11. Covas DT, Haddad SK. HIV. In: Bordin JO, Langhi DM Jr, Covas DT. Hemoterapia - Fundamentos e Prática. São Paulo: Atheneu; 2007. p. 487-99.

12. Zetola NM, Engelman J, Jensen TP, Klausner JD. Syphilis in the United States: an update for clinicians with an emphasis on HIV coinfection. Mayo Clin Proc. 2007;82(9):1091-102. http://dx.doi.org/10.4065/82.9.1091. PMid:17803877.

13. Vaz AJ, Takei K, Bueno EC. Imunoensaios: fundamentos e aplicações. Rio de Janeiro: Guanabara Koogan; 2007.

14. Phikulsod S, Oota S, Tirawatnapong T, Sakuldamrongpanich T, Chalermchan W, Louisirirotchanakul S, et al. One-year experience of nucleic acid technology testing for human immunodeficiency virus Type 1 , hepatitis $C$ virus, and hepatitis $B$ virus in Thai blood donations. Transfusion. 2009;49(6):1126-35. http://dx.doi.org/10.1111/j.15372995.2009.02176.x. PMid:19392770.

15. Kucirka LM, Sarathy $H$, Govindan $P$, Wolf JH, Ellison TA, Hart LJ, et al. Risk of window period hiv infection in high infectious risk donors: systematic review and meta-analysis. Am J Transplant. 2011;11(6):1176-87. http://dx.doi.org/10.1111/j.16006143.2010.03329.x. PMid:21366859.

16. Barreto CC, Sabino EC, Gonçalez TT, Laycock ME, Pappalardo BL, Salles NA, et al. Prevalence, incidence, and residual risk of human immunodeficiency virus among community andreplacement first-time blood donors in São Paulo, Brazil. Transfusion. 2005;45(11):1709-14. http://dx.doi.org/10.1111/j.15372995.2005.00575.x. PMid:16271094.

17. Brasil. Ministério da Saúde. Boletim epidemiológico HIV/Aids. Ministério da Saúde; 2017. [citado 2018 Abr 18]. Disponível em: http://www. aids.gov.br/pt-br/pub/2017/boletimepidemiologico-hivaids-2017.

18. Silva LS da, Santos DV, Brietzke CB, Jacociunas LV. Prevalence of hiv infection, Syphilis, and Syphilis/HIV coinfection in blood donors from a blood bank of Porto Alegre, southern Brazil. Clin Biomed Res. 2017;37(4): 275-280.

19. Costa M, De Souza VM, Trindade DMS, Portes APGS, Sampaio RA. Soroprevalência de HIV $1 / 2$ em doadores de sangue provenientes do hemocentro de ceres-go, entre janeiro de 2010 a dezembro de 2013. Refacer. 2016;5(1).

20. Polejack L, Seidl EMF. Monitoramento e avaliação da adesão ao tratamento antirretroviral para HIV/aids: desafios e possibilidades. Cien Saude Colet. 2011;5(Supl. 1):1201-8.

21. Pereira GC, Bonafé SM.

Soroprevalência para doenças infectocontagiosas em doadores de sangue da cidade de maringá, paraná. Uningá Review. 2018;43(1):16-24.

22. Azevedo DR. Importância da introdução do NAT (Nucleic Acid Test) HIV/HCV nos serviços de hemoterapia do Brasil [monografia Biomedicina]. Brasília: Universidade Católia de Brasília; 2014.

23. Brasil. Ministério da Saúde. Agência Nacional de Vigilância Sanitária. Rede Brasileira de Avaliação de Tecnologias em Saúde. O teste de amplificação de ácidos nucléicos (NAT) e as demais estratégias para detecção dos vírus HIV-1 e HCV na triagem de sangue doado. Boletim Brasileiro de Avaliação de tecnologias em Saúde. Brasília: 2007;3.

24. Velati C, Romanò L, Fomiatti L, Baruffi L, Zanetti AR. Impact of nucleic acid testing for hepatitis $B$ vírus, hepatitis $C$ vírus and human immunodeficiency vírus on the safety of blood supply in Italy: a 6-year survey. Transfusion. 2008;48(10):2205-13. http://dx.doi.org/10.1111/j.15372995.2008.01813.x. PMid:18631163.

25. Lima DS. Estudo comparativo de metodologias de triagem para HIV e HCV em doadores de sangue [projeto de pesquisa]. Brasília: Pós-graudação em Hematologia da Universidade de Brasília; 2011.

26. Gonçalves KI, Souza EM, Modesto LS, Fonseca AF, Alcântara KC. Soroprevalência de HIV1/2 entre doadores de sangue de GoiâniaGoiás. RBAC. 2006;38(4):263-66. 
27. Busch MP, Glynn SA, Stramer SL, Strong DM, Caglioti S, Wright DJ, et al. A new strategy for estimating risks of transfusiontransmitted viral infections based on rates of detection of recently infected donors. Transfusion. 2005;45(2):25464. http://dx.doi.org/10.1111/ j.1537-2995.2004.04215.x. PMid:15660836.
28. Ribeiro ATB, Jacociunas LV. A coinfecção sífilis/HIV e sua importância no rastreamento sorológico em bancos de sangue. Clin Biomed Res. 2016;36(2):101109.

29. Miller LE. Laboratory Diagnosis of HIV Infection. In: Stevens CD. Clinical immunology and serology: a laboratory perspective. 3rd ed. Philadelphia: F.A. Davis Company; 2010. p. 476.

30. Fundação Oswaldo Cruz (Fiocruz). Instituto de Tecnologia em Imunobiológicos. Fiocruz; 2018. [citado 2018 Out 23]. Disponível em: https://www.bio.fiocruz.br/index.php/ noticias/641-ministerio-da-saudetorna-obrigatorio-o-teste-nat.

Recebido: 10 set, 2018 Aceito: $20 \mathrm{dez}, 2018$ 